\title{
Nuclear magnetic resonance study of sea-water freezing mechanisms: 2. Temperature dependence of relaxation time of protons in sea-ice brine
}

\author{
N.A. MEL'NICHENKO \\ Oceanological Department, Far Eastern Federal University (DVGU), Vladivostok, Russia \\ E-mail: melnich@geo.dvgu.ru
}

\begin{abstract}
Results of determinations of proton magnetic relaxation time $\left(T_{1}\right)$ in the liquid phase of frozen sea water at temperatures between $-2^{\circ} \mathrm{C}$ and $-38^{\circ} \mathrm{C}$, with variable rate and direction of temperature change, are presented. Temperature hysteresis corresponding to the crystallization range of certain sea-water salts, mainly $\mathrm{NaCl}$ which partially precipitates as the crystalline hydrate $\mathrm{NaCl} \cdot 2 \mathrm{H}_{2} \mathrm{O}$ at temperatures below $-23^{\circ} \mathrm{C}$, is detected in the temperature dependence of $T_{1}$, as in the analogous dependence of brine content. It is shown that formation of crystalline hydrates in brine is preceded by complete solvation of ions at -5 to $-6^{\circ} \mathrm{C}$. The main causes of hysteresis in temperature dependence of $T_{1}$ and the extension of loop limits compared with the analogous loop for liquid brine content are indicated. Additional potentialities of using the nuclear magnetic resonance method for investigating sea-ice properties are presented.
\end{abstract}

\section{INTRODUCTION}

Knowledge of brine content in sea-ice pores and brine composition under various sea-water freezing conditions is important for understanding the physico-chemical properties of sea ice (Melnichenko and Slobodyuk, 2013).

Nuclear magnetic resonance (NMR) by protons and other nuclei is the most informative method for studying sea-water freezing processes because it is non-destructive and does not require brine drainage or the addition of chemical reagents. Hence, it is presently widely used to study the porosity of natural sea ice, including under field conditions (e.g. Edelstein and Schulson, 1991; Callaghan and others, 1999; Eicken and others, 2000; Menzel and others, 2000).

Additional data on the microstructure of solutions, primarily brines, can be obtained by measuring the proton spin relaxation time $\left(T_{1}\right)$ in the liquid phase of sea ice since $T_{1}$ depends on the interrelated rate of molecular motions and microstructure of the solution. Relaxation processes in fresh water in simple water solutions have been well studied (e.g. Hindman and others, 1973; Lang and Lüdemann, 1977; Chizhik, 1991). Results of a study of the temperature dependence of proton relaxation time in sea water and water solutions, with various functional presentations, are given by Melnichenko and others (2009). However, information about relaxation processes in sea ice is lacking in the literature. This information may be useful for establishing the characteristics of the sea-water freezing mechanism.

To develop investigations begun earlier (Melnichenko and others, 1981), we present the results of additional experiments to study the temperature dependence (TD) of proton magnetic relaxation time in the liquid phase of frozen sea water within temperature limits covering the range of existence of sea ice under natural conditions. This approach, combined with earlier investigations, makes it possible to detail the sea-water freezing mechanism.

\section{METHODS}

Measurements of $T_{1}$ were taken using an improved null method known as inversion of nuclear magnetization, which does not require high linearity of the spectrometer receiver or use of the statistical treatment of exponential curves, and minimizes the uncertainty in determining the moment of passage of the signal through zero $\left(\tau_{0}=\ln ^{2} \cdot T_{1}\right)$. Measurements were made on a home-made pulse NMR spectrometer (prepared by the author at DVGU, Vladivostok, Russia) with automatic stabilization of resonance conditions, and large homogeneous magnetic and radiofrequency fields. The width spin-echo signal at half its intensity was $\sim 10 \mathrm{~mL}$. The signal-to-noise ratio was $\sim 500$. The interval between pulse sequences $\left(180^{\circ}-90^{\circ}-180^{\circ} \ldots\right)$ for the well-known null method (M-G method) was $\sim 6 T_{1}$.

The scatter of the $T_{1}$ values in distilled water in a series of 200 measurements at $25^{\circ} \mathrm{C}$ relative to an average value of $3.524 \mathrm{~s}$, which is in good agreement with Hindman and others' (1973) measurements equal to $3.52 \mathrm{~s}$, did not exceed $0.005 \mathrm{~s}$. The errors in determining relaxation time were $1 \%$ and $2 \%$ respectively, and errors in determining temperature were $<0.2 \mathrm{~K}$. Oxygen dissolved and adsorbed on the ampoule glass, which affects the relaxation rate, was thoroughly removed prior to relaxation measurements by multiple repetition of the freezing-vacuum-pumping-thawing-heating cycle. The sample was cooled by liquid nitrogen vapors that bathed the ampoule with the sample from the top and bottom to eliminate a temperature gradient along it. The temperature of the sample was taken equal to the temperature of the coolant in a Dewar flask, measured by a calibrated thermocouple located next to the lower end of the ampoule since direct measurement of the sample is impossible when the spectrometer is operating. Control measurements of the temperature of the coolant and water in the sample, using a platinum thermal resistor isolated from sea water taken with the spectrometer receiver and transmitter disconnected, gave a discrepancy not exceeding the indicated error at $-60^{\circ} \mathrm{C}$. The amplitude of the nuclear induction signals and the relaxation time $T_{1}$ after each temperature change were measured only after establishing equilibrium, when the values did not change for 15-20 min. Surface water from the Atlantic Ocean and Philippine Sea with salinity $\sim 35 \%$ was investigated. 


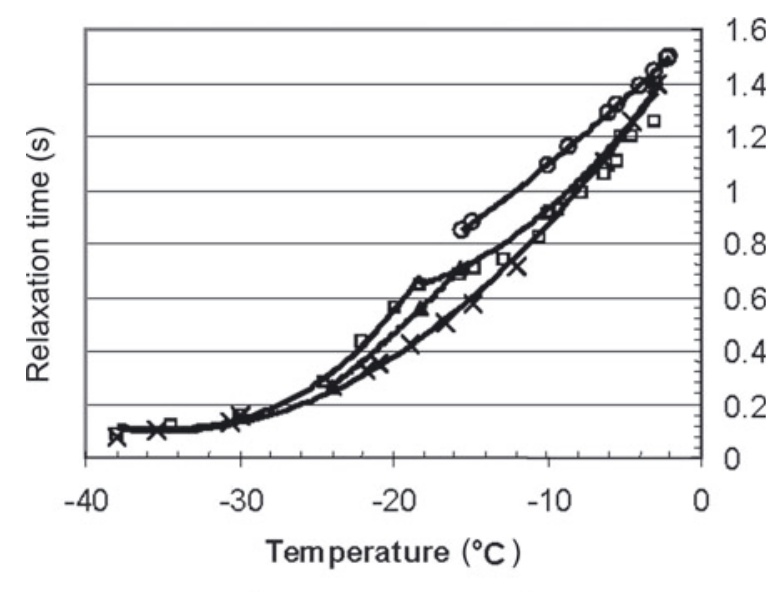

$0-1$ ㅁ $-2 \wedge-3 \times-4$

Fig. 1. Temperature dependence of $T_{1}$ in supercooled sea water and in brine of frozen sea water. Curve 1: $T_{1}$ in supercooled sea water; curve 2: $T_{1}$ in ice brine during smooth temperature decrease; curve 3: sharp temperature decrease to $-15^{\circ} \mathrm{C}$ followed by gradual temperature decrease; curve 4 : temperature increase from $-60^{\circ} \mathrm{C}$.

\section{RESULTS AND DISCUSSION}

Information on sea-water freezing processes can be obtained from relaxation measurements, and particularly from measurements of the proton spin-lattice relaxation time $T_{1}$ (Table 1). This parameter, characterizing the rate of establishment of equilibrium in a system of magnetic moments of hydrogen nuclei (spin system), is sufficiently sensitive to changes in the solution's microstructure at the molecular level. The results of measuring the TD of the relaxation time of hydrogen nuclei $T_{1}$ in limits from -2 to $-38^{\circ} \mathrm{C}$ are given in Figure 1. The figure also shows a fragment of the TD for $T_{1}$ in supercooled sea water (curve 1), which is actually its smooth continuation at positive temperatures (Melnichenko and others, 2009).

It follows from NMR theory that the relaxation rate $\left(1 / T_{1}\right)$ in aqueous solutions is proportional to the correlation time $(\tau)$ separating two adjacent orientations of water molecules and protons. Accordingly, the inverse quantity, i.e. the relaxation time $\left(T_{1}\right)$, is proportional to the mobility of water molecules. In turn, the relaxation time in sea water is a function of two factors, temperature and salinity: $T_{1}=f(T, S)$. With decreasing temperature, $T_{1}$ decreases due to a decrease in the intensity of molecular motions and with increasing salinity; it decreases owing to binding of water molecules by ions with the formation of hydration shells.

A comparison of the temperature dependences of $T_{1}$ in supercooled sea water, in which salinity is constant and equal to $\sim 35 \%$ (curve 4 in Fig. 1), with analogous dependences in frozen sea-water brine shows that the effect of salinity on $T_{1}$ far outweighs that of the temperature factor.

Figure 1 also shows that the $T_{1}$ values in the frozen seawater liquid phase, as well as the brine content, depend not only on the rate of temperature change but also on the direction of that change. Higher $T_{1}$ values (curve 2) are obtained with a smooth temperature decrease, but $T_{1}$ changes more smoothly (curve 4) with a temperature increase from $-60^{\circ} \mathrm{C}$. Intermediate $T_{1}$ values (curve 3) are obtained with a sharp cooling of the sample from $-15^{\circ} \mathrm{C}$.

The occurrence of a break in the curve of the temperature dependence of $T_{1}$ can be explained by a considerable

Table 1. Experimental data of relaxation measurements in frozen sea water

\begin{tabular}{|c|c|c|c|c|c|c|c|}
\hline Temp. & $\begin{array}{l}\text { Smooth cooling } \\
\text { from }-2{ }^{\circ} \mathrm{C}\end{array}$ & $\begin{array}{c}\text { Sharp temp. } \\
\text { decrease to }-15^{\circ} \mathrm{C}\end{array}$ & $\begin{array}{l}\text { Smooth cooling } \\
\text { from }-21^{\circ} \mathrm{C}\end{array}$ & Temp. & $\begin{array}{l}\text { Heating from } \\
\quad-38^{\circ} \mathrm{C}\end{array}$ & Temp. & $\begin{array}{l}\text { Supercooled } \\
\text { sea water }\end{array}$ \\
\hline \multirow[t]{2}{*}{${ }^{\circ} \mathrm{C}$} & $T$ & $T$ & $T_{1}$ & & $T_{1}$ & $T$ & $\mathrm{~T}_{1}$ \\
\hline & $\mathrm{s}$ & ${ }^{\circ} \mathrm{C}$ & $\mathrm{s}$ & ${ }^{\circ} \mathrm{C}$ & $\mathrm{s}$ & ${ }^{\circ} \mathrm{C}$ & $\mathrm{s}$ \\
\hline-3.1 & 1.400 & -15.6 & 0.700 & -38.2 & 0.099 & -2.1 & 1.503 \\
\hline-5.2 & 1.210 & -24.2 & 0.270 & -30.8 & 0.144 & -3.1 & 1.439 \\
\hline-5.5 & 1.200 & -28.0 & 0.200 & -30.1 & 0.152 & -4.1 & 1.390 \\
\hline-6.2 & 1.100 & & & -30.8 & 0.144 & -5.6 & 1.310 \\
\hline-8.0 & 1.050 & & & -30.1 & 0.152 & -6.1 & 1.290 \\
\hline-9.3 & 0.981 & & & -23.9 & 0.267 & -8.9 & 1.150 \\
\hline-10.1 & 0.929 & & & -21.8 & 0.327 & -10.3 & 1.090 \\
\hline-10.3 & 0.910 & & & -22.0 & 0.360 & -15.2 & 0.883 \\
\hline-10.8 & 0.903 & & & -19.0 & 0.413 & -15.9 & 0.852 \\
\hline-15.1 & 0.735 & & & -14.8 & 0.573 & & \\
\hline-15.8 & 0.700 & & & -12.2 & 0.713 & & \\
\hline-18.3 & 0.640 & & & -6.0 & 1.107 & & \\
\hline-18.7 & 0.640 & & & -5.38 & 1.250 & & \\
\hline-20.1 & 0.557 & & & -2.80 & 1.400 & & \\
\hline-21.1 & 0.487 & & & & & & \\
\hline-22.2 & 0.430 & & & & & & \\
\hline-23.2 & 0.367 & & & & & & \\
\hline-24.6 & 0.287 & & & & & & \\
\hline-30.2 & 0.170 & & & & & & \\
\hline-34.7 & 0.111 & & & & & & \\
\hline-38.2 & 0.099 & & & & & & \\
\hline
\end{tabular}


decrease in the mobility of molecules being retained by seawater ions as a consequence of increased salinity of brine in ice pores. The increased brine salinity results from partial freezing-out of pure water and pore size reduction. The rate of freezing-out of pure water from brine decreases with pore size reduction, and the curves of the temperature dependence of $T_{1}$ as well as those of relative brine content $\left(Q_{\mathrm{I}}\right)$ reach a plateau at temperatures lower than $-25^{\circ} \mathrm{C}$.

After partial precipitation of $\mathrm{NaCl} \cdot 2 \mathrm{H}_{2} \mathrm{O}$ and other crystalline hydrates, the relative proportion of pure water in ice cells increases, leading to further freezing-out of part of the brine and thus to a further reduction in pore size and increase in brine salinity. The relative proportion of water molecules not bound with ions decreases with increasing brine concentration, leading to a decrease in the total mobility of water molecules and a decrease in $T_{1}$.

The different character of the temperature dependences of $T_{1}$ within the temperature region near the $\mathrm{NaCl}$ eutectic point pertaining to different values of the initial temperature, freezing rate and direction of temperature change, as with the analogous dependences of $Q_{1}$, can be explained by the meta-stability of crystalline hydrates in ice brine. It is not precluded that for this reason the state of brine in a $\mathrm{NaCl}$ solution and in sea water is what has been called a quasibrine layer (Cho and others, 2002). Therefore, it is more correct to refer the effect of $\mathrm{NaCl}$ precipitation from sea-ice brine not to one fixed temperature but to a temperature interval $\left(-21\right.$ to $\left.-24^{\circ} \mathrm{C}\right)$.

The more extended hysteresis loop in the temperature dependence of $T_{1}$ in the -8 to $-24^{\circ} \mathrm{C}$ interval and the shift of its maximum relative to the analogous loop on the brine content curve toward higher temperatures are evidently due to the dependence of the brine microstructure and salinity on the history of the ice sample, i.e. on the structure 'precursor'. Structural changes accompany all processes in brine at all stages.

The increase in the extension of the hysteresis loop limits of the temperature dependence of $T_{1}$ compared with the analogous loop for $Q_{1}$ is due to a change in mobility of water molecules and ions because of changes in the structure, salt composition and forms of crystalline hydrates. Thus, one of the conditions on which the sea-water freezing process depends is that the complete solvation limits of ions in ice brine with salinity higher than $84 \%$ are reached at $\sim-5^{\circ} \mathrm{C}$. On attaining this condition, almost all water molecules pass into ion influence zones, after which processes of crystalline hydrate formation begin, with subsequent partial precipitation.

A similar explanation is given by Cho and others (2002), who suggest that kinetic effects precede the formation of crystalline hydrates. This is likely, given that, on reaching the complete solvation limits, the mobility of water molecules and of ions themselves decreases sharply. The result is the same in both cases, due to counterbalancing Dufour and Soret effects.

Other precipitating salts, i.e. besides $\mathrm{NaCl} \cdot 2 \mathrm{H}_{2} \mathrm{O}$, can substantially affect a change in $T_{1}$ at temperatures below $-23^{\circ} \mathrm{C}$. Primarily these are magnesium salts, which affect the proton relaxation rate and, accordingly, the solution's microstructure (Melnichenko, 2007). According to Gitterman's (1937) data, up to $15 \%$ of $\mathrm{MgSO}_{4}$ precipitates from brine near the $\mathrm{NaCl}$ eutectic point. However, other magnesium ions are precipitated at lower temperatures (Fig. 2).
The formation of ion pairs in sea water is caused by Coulomb interaction forces, weakened by a 'coat' of water molecules in hydration shells. The distance between ions decreases, and Coulomb interaction forces increase, with increasing solution concentration. Naturally, after partial precipitation of salts, the remaining ions change 'partners' to provide stable equilibrium in the system. These processes are not instantaneous, but proceed in accordance with the Maxwell distribution of the speeds of molecules and ions. Therefore, there are no grounds for supposing the existence of a fixed temperature for the formation of a particular crystalline hydrate in the complex sea-ice brine system.

Thus, the main characteristic of the sea-water freezing mechanism and formation of the salt composition of ice brine is the formation of crystalline hydrates of salts, mainly $\mathrm{NaCl} \cdot 2 \mathrm{H}_{2} \mathrm{O}$, partially participating from brine at temperatures below $-23^{\circ} \mathrm{C}$. Precipitation of calcium carbonate and sodium sulphate from ice brine in the temperature interval from the freezing point to the $\mathrm{NaCl}$ eutectic point has minimal effect on the salinity of sea-ice brine.

The occurrence of 'hysteresis' in graphs of the temperature dependences of the relative brine content and relaxation time is due to meta-stability of the formation of crystalline hydrates, which can lead to noticeable differences in the values of the content of ice brine and its salinity at the same ice temperatures near the $\mathrm{NaCl}$ and $\mathrm{Na}_{2} \mathrm{SO}_{4}$ eutectic points, especially when there are sharp changes in the rate of ice formation and direction of temperature change. An additional contribution to the occurrence of hysteresis may be made by the manifestation of cross-thermal diffusion effects near the eutectic points and the blocking of ice shells.

However, the sea-water freezing mechanism includes not only the formation of crystalline hydrates in brine and their precipitation but also complete solvation of most ions in ice brine at salinity $\sim 80-90 \%$ (Melnichenko, 2007). These processes can change the thermophysical properties of brine and ice as a whole since porosity and brine content are the most important parameters of sea ice. The relaxation time $T_{1}$ as well as the molecular diffusion coefficient $D$ is highly dependent on ice porosity. However, $T_{1}$ can be measured with much greater accuracy than $D$. Measurement of $D$ was used by, for example, Callaghan and others (1999) to study the porosity of sea-ice samples.

\section{CONCLUSION}

The pulsed NMR method using the Earth's magnetism offers the best prospects for studying sea ice under natural conditions. Under field conditions, this gives on-site measurements two additional advantages. First, there is no need to transport samples, whereby part of the brine may be lost even despite careful observance of the conditions described by Edelstein and Schulson (1991), Eicken and others (2000) and Menzel and others (2000). Second, dielectric losses related to large electrical conductivity of highly concentrated ice brines are minimized at low frequencies. Variants of NMR sea-ice analysers based on the Earth's magnetism are presented by Callaghan and others (1999).

\section{ACKNOWLEDGEMENT}

I thank Jack Slep for English language assistance and V.I. Chizhik for useful discussion. This project was supported by the Scientific Fund of EEFU. 

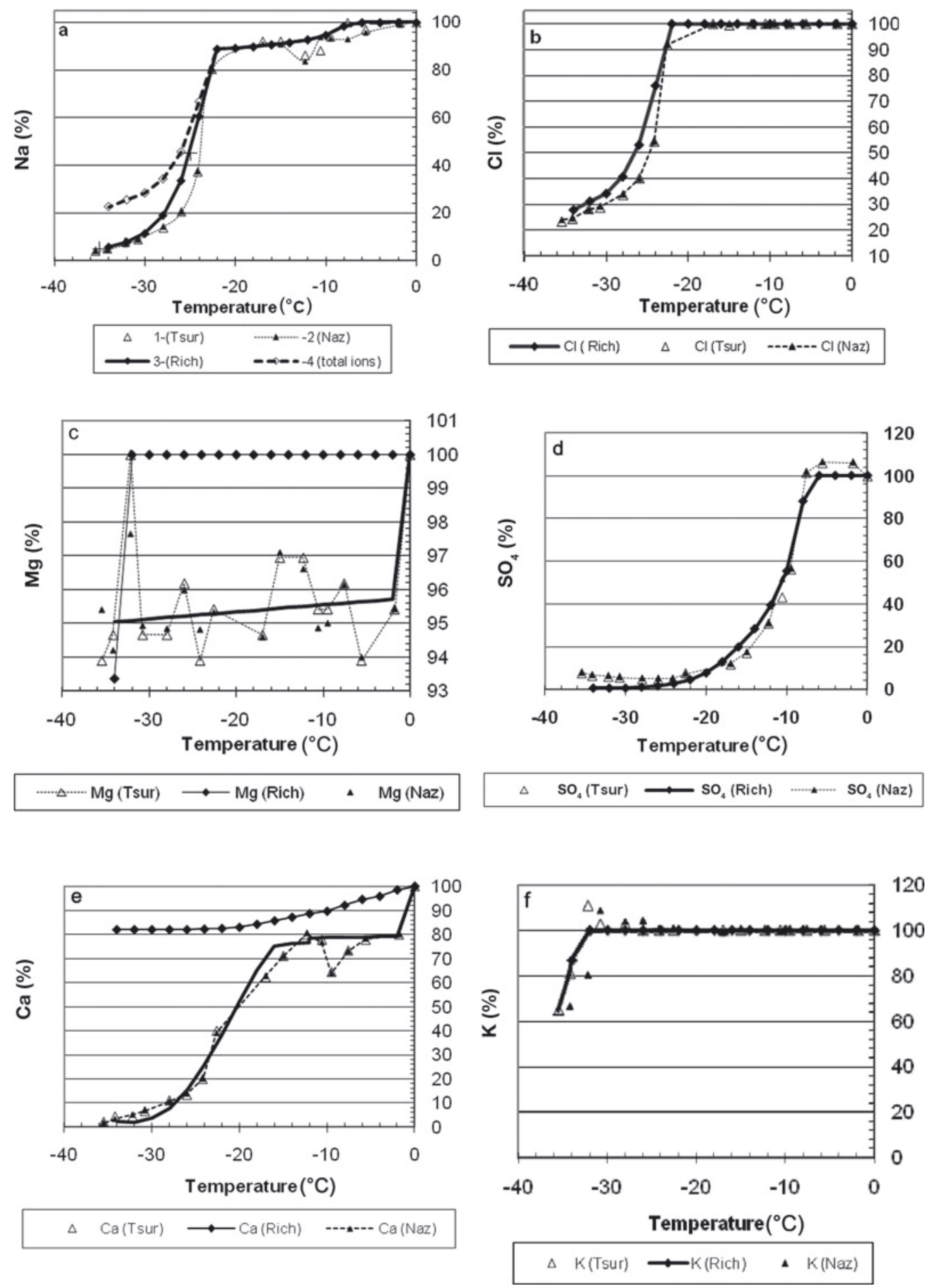

Fig. 2. Temperature dependences of relative major-ion content in ice brine, based on literature data. (a) $\mathrm{Na}^{+}$, (b) $\mathrm{Cl}^{-}$, (c) $\mathrm{Mg}^{2+}$, (d) $\mathrm{SO}_{4}{ }^{2-}$, (e) $\mathrm{Ca}^{2+}$ and (f) $\mathrm{K}^{+}$. Open triangles: Tsurikov and Tsurikova (1972); diamonds: Richardson (1976); filled triangles: Nazintsev (1974). 100\% corresponds to the ion concentration in sea water with salinity $35 \%$.

\section{REFERENCES}

Callaghan PT and Eccles CD (1996) NMR studies on Antarctic sea ice. Bull. Magn. Reson., 18 (1-2), 62-64

Callaghan PT, Eccles CD and Seymour JD (1997) An earth's field nuclear magnetic resonance apparatus suitable for pulsed gradient spin echo measurements of self-diffusion under Antarctic conditions. Rev. Sci. Instr., 68(11), 4263 (doi: 10.1063/ 1.1148340)

Callaghan PT, Dykstra R, Eccles CD, Haskell TG and Seymour JD (1999) A nuclear magnetic resonance study of Antarctic sea ice brine diffusivity. Cold Reg. Sci. Technol., 29(2), 153-171 (doi: 10.1016/S0165-232X(99)00024-5)
Chizhik VI (1991) [Nuclear magnetic relaxation]. Nauka, Leningrad [in Russian]

Cho H, Shepson PB, Barrie LA, Cowin JP and Zaveri R (2002) NMR investigation of the quasi-brine layer in ice/brine mixtures. J. Phys. Chem. B, 106(43), 11226-11232 (doi: 10.1021/ jp020449+)

Edelstein WA and Schulson EM (1991) NMR imaging of salt-water ice. J. Glaciol., 37(125), 177-180

Eicken H, Bock C, Wittig R, Miller H and Poertner HO (2000) Magnetic resonance imaging of sea-ice pore fluids: methods and thermal evolution of pore microstructure. Cold Reg. Sci. Technol., 31(3), 207-225 (doi: 10.1016/S0165-232X (00)00016-1) 
Gitterman KE (1937) Thermal analysis of seawater. CRREL Rep. TL 287

Hindman JC, Svirmickas A and Wood M (1973) Relaxation processes in water: a study of the proton spin-lattice relaxation time. J. Chem. Phys., 59(3), 1517-1522 (doi: 10.1063/1.1680209)

Lang E and Lüdemann H-D (1977) Pressure and temperature dependence of the longitudinal proton relaxation times in supercooled water to $-87^{\circ} \mathrm{C}$ and 2500 bar. J. Chem. Phys., $\mathbf{6 7}(2)$, 718-723 (doi: 10.1063/1.434878)

Mel'nichenko NA (2007) Hydration numbers of sea water basic ions found by the pulse method of proton NMR. J. Struct. Chem., 48(3), 479-485

Mel'nichenko N and Slobodyuk AB (2013) Nuclear magnetic resonance study of sea-water freezing mechanisms: 1 . Temperature dependence of relative brine content in sea ice. J. Glaciol., 59(216), 711-718

Mel'nichenko NA, Mihailov VI and Chizhik VI (1981) Studies of the temperature-dependence of the brine content of sea ice by the pulse NMR method. CRREL Draft Transl. 757. [Translated from Okeanologiya, 19(5) [1979], 811-814]

Mel'nichenko NA, Chizhik VI, Vyskrebentsev AS and Tyuveev AV (2009) The temperature dependences and methods for the functional representation of the rates of proton magnetic relaxation in aqueous solutions of electrolytes. Russ. J. Phys. Chem., 83(8), 1307-1314 (doi: 10.1134/S0036024409080111) Menzel, MI, Han S-I, Stapf S and Blümich B (2000) NMR characterization of the pore structure and anisotropic selfdiffusion in salt water ice. Magn. Reson. Imaging, 143(2), 376-381

Nazintzev UL (1974) [Quantity relations in phase composition of sea ice]. Probl. Arkt. Antarkt., 45, 62-67 [in Russian]

Richardson C (1976) Phase relationships in sea ice as a function of temperature. J. Glaciol., 17(77), 507-519

Tsurikov VL and Tsurikova AP (1972) O soderzhanii rassola v morskikh I'dakh (sostoyaniye voprosa) [On the brine content of sea ice (state of the problem)]. Okeanologiia, 12(5), 792-802

MS received 17 December 2012 and accepted in revised form 24 April 2013 